\title{
O Perfeito Composto: Principais Efeitos de Estilo nas Notícias ELETRÔNICAS ITALIANAS
}

\author{
EVA BOUQUARD \\ SONIA CRISTINA REIS \\ CláUdia Fátima Martins
}

RESUMO: O presente artigo traz algumas reflexões acerca do uso do Perfeito Composto em notícias eletrônicas narrativizadas, extraídas dos jornais italianos Corriere della Sera, La Repubblica e La Stampa. ${ }^{1}$ O objetivo é apresentar efeitos estilísticos do Perfeito Composto, a saber, o inclusivo, o completo e o aorístico, resultantes da categoria aspectual que esse tempo verbal produz em notícias narrativizadas. PALAVRAS-CHAVE: aspectual; efeitos estilísticos; perfeito composto; língua italiana.

ABSTRACT: Il presente articolo espone delle riflessioni sull'uso del Perfetto Composto in notizie elettroniche "narrativizzate", tratte dai giornali italiani Corriere della Sera, La Repubblica e La Stampa. L'obiettivo è presentare alcuni effetti stilistici del Perfetto Composto, come l'inclusivo, il completo e l'aoristico, risultanti dalla categoria aspettuale di tale tempo verbale presenti negli articoli analizzati. PAROLE CHIAVE: aspettuale; effetti stilistici; perfetto composto; lingua italiana. 
ABSTRACT: This current essay brings some reflections on the perfec compound tense in narrativizes electronic news which were taken from the following italian newspaper Corriere della Sera, La Repubblica e La Stampa. Itis purpose is to present some of the perfect compound stylistic effects, namely the inclusive, the complete and the aoristic, resulting from the aspectual category produced by this verb tense in narrativizes news.

KEYWORDS: aspectual; stylistic effects; perfect compound; Italian language. 
estudo de Bertinetto ${ }^{2}$ sobre o aspecto dos verbos no modo indicativo explica que a definição tradicional do Perfeito Composto o descreve como marcando o "passado do presente", ou seja, como o tempo que indica "uma ação, estado ou modo de ser já completo, mas considerado em relação com o presente”.

Contudo, essa não seria a única função absorvida pelo Perfeito Composto. O motivo é que, enquanto tempo empregado na sua acepção aspectual originária, ou seja, para designar a completitude em relação ao momento da enunciação, o Perfeito Composto é também selecionado para se obter os efeitos estilísticos e discursivos proporcionados pelo seu valor aspectual.

Desse modo, ao se estudar o passado verbal da língua italiana, ocorreu a necessidade de se adotar uma nomenclatura para o Perfeito Composto, porque a denominação atual dos tempos verbais italianos é heterogênea (BERTINETTO, 1986). Por este motivo, segue-se a nomenclatura utilizada por esse autor, ou seja, a de Perfeito Composto para a forma estrutural do Passato Prossimo, porque permite aludir às caracterizações aspectuais e temporais predominantes desse tempo verbal.

Assim, dado que esse artigo trata dos efeitos de estilo do Perfeito Composto, visando a facilitar a exposição dos argumentos apresentados, utilizou-se, também, esta mesma nomenclatura para tratar das funções aspectuais deste Perfeito. Portanto, utiliza-se a terminologia Perfeito Composto para as construções do Passato Prossimo, que é formado por um verbo auxiliar conjugado no presente do indicativo somado a um particípio. 
Dado que essa forma estrutural do Perfeito Composto, além de expressar tempo, admite também interpretações de natureza aspectual, recorreu-se a denominações específicas para os efeitos estilísticos da categoria de aspecto alusivos a este tempo.

Utiliza-se o termo 'efeito de estilo', de acordo com o linguista francês Benveniste, ${ }^{3}$ quando o Perfeito Composto sair do campo do discurso e passar para o plano da narrativa, como também para tratar dos resultados aspectuais e temporais que tanto o Perfeito Simples como o Perfeito Composto produzem em um texto narrativo.

As terminologias específicas de efeitos de estilo aspectuais, utilizadas neste trabalho, remetem às funções do Perfeito Composto que são as funções aorística, inclusiva e completa. Assim, se usará uma terminologia distinta para cada uma destas propriedades como "Perfeito Composto Aorístico", "Perfeito Composto Inclusivo", "Perfeito Composto Completo", respectivamente.

Estabelecidos esses pontos preliminares, a primeira questão que se coloca quanto ao emprego deste Tempo Composto diz respeito ao uso dessa forma linguística com função aspectual.

Considera-se aspecto a função do Perfeito Composto que representa um período como sendo anterior ao momento no qual se realiza a conclusão de um determinado acontecimento, ou seja, uma ação que expressa uma anterioridade temporal no enunciado e é acompanhada de significado perfectivo.

A fim de esclarecer o que se entende com a palavra tempo, faz-se referência aos conceitos de Benveniste (1994) sobre tempo físico e tempo linguístico. Explica o linguista francês que o tempo físico é o tempo correlato ao homem, com uma duração variável, e que cada indivíduo o mede pelo grau de suas emoções e pelo ritmo de sua vida interior. O tempo linguístico instalado no discurso depende de dispositivos por meio dos quais o enunciador dá a idéia de tempo, produzindo os efeitos de estilo de aproximação e distanciamento.

Na fundamentação das noções de tempo linguístico e de tempo físico, Benveniste entende que a língua ordena o tempo a partir de um eixo na instancia do discurso. Logo, o tempo presente é usado como linha de separação entre o que não é mais presente e o que vai sê-lo. Essas duas referências não se relacionam ao tempo, mas às visões sobre o tempo projetado para trás e para frente.

Assim, considera-se que o tempo físico se refere ao período estabelecido pelo calendário, ao passo que tempo linguístico se refere ao tempo utilizado nas narrativas. Estes conceitos foram necessários para poder relacionar o Perfeito Composto ora com o tempo físico, ora com o tempo linguístico.

Segundo o linguista Bertinetto (1986), expressar a idéia de tempo não é a única função absorvida pelo Perfeito Composto na língua italiana, porque o valor aspectual do Perfeito 
Composto manifesta uma duplicidade de funções que produzem diferentes efeitos nos enunciados.

Nessa produção de efeitos, o enunciador utiliza determinados marcadores temporais para garantir os estilos que ele deseja produzir sobre o seu leitor. Os exemplos a seguir demonstram dois resultados diferentes produzidos pelo Perfeito Composto, conforme colocados por Bertinetto ${ }^{4}$ :

(a) Massimo ha mangiato il gelato da dieci minuti.

(b) Massimo ha mangiato il gelato dieci minuti prima.

Nos exemplos acima, no enunciado (a) o marcador temporal mede o intervalo decorrido entre o final do evento e o momento da enunciação, enquanto em (b) mede o intervalo transcurso entre o final do evento e um instante qualquer que não pode coincidir com o momento da enunciação.

Contudo, esse mesmo Perfeito, se fosse utilizado em um contexto que localizasse o evento como no exemplo (b), desenvolveria outra função aspectual, que seria a aorística, que se assemelha à categoria do Perfeito Simples, como demonstra Bertinetto na frase:

(c) Massimo ha mangiato il gelato dieci minuti prima che tu arrivassi. Tu sei arrivato alle cinque. Dunque, Massimo ha mangiato il gelato dieci minuti prima delle cinque.

Essas colocações permitem considerar que o Perfeito Composto, por aproximar o acontecimento sempre do momento da enunciação, pode corresponder exatamente ao valor que o Perfeito Simples expressaria no seu valor aspectual aorístico. Assim sendo, o efeito estilístico expresso pelo Perfeito Composto envolve a sua relação com o marcador temporal e com o momento da enunciação.

É a partir desta reflexão, portanto, que se selecionaram para análise e se colocaram neste artigo três efeitos estilísticos resultantes da categoria de aspecto nas notícias italianas. Trata-se dos efeitos de inclusividade, de completitude e de aorístico.

No parágrafo a seguir, se exemplifica que, no primeiro efeito, ou seja, o inclusivo, o acontecimento ainda não foi concluído no momento da enunciação. No segundo, que é o de completitude, o evento narrado passa pelo momento da enunciação; e no terceiro, o aorístico, o evento não passa por esse momento.

A primeira das acepções, ou seja, a inclusiva, consiste em um acontecimento que perdura no momento da enunciação, permitindo um resultado imperfectivo ao enunciado. Considera-se o seguinte exemplo fornecido por Bertinetto ${ }^{5}$ :

\footnotetext{
4. BERTINETTO, p. 412.

5. BERTINETTO, p. 418.
} 
(e) Negli ultimi due mesi, Bernardo ha vissuto in condizioni molto disagevoli.

O exemplo acima leva-nos a refletir que, normalmente, o Perfeito Composto implica a conclusão do acontecimento dentro de um momento de referência, por causa de sua natureza predominantemente aspectual. Contudo, o que perdura, no momento da enunciação, não é o resultado do fato, mas o evento em si mesmo por causa do marcador temporal negli ultimi due mesi, que aproxima o acontecimento ha vissuto ao momento da enunciação.

Neste efeito estilístico, o Perfeito Composto não implica necessariamente a conclusão do evento representado no momento da enunciação, mas a continuidade, o perdurar desse evento também no momento enunciativo.

Esse estilo inclusivo do Perfeito Composto pode ser produzido no enunciado sempre que existirem expressões temporais de tempo que indiquem um acontecimento começado antes do momento que se enuncia, mas que continua nesse mesmo momento. Assim, um dos exemplos destes marcadores são as expressões até agora, da última vez, nos últimos anos, pois indicam a continuidade de um acontecimento, ainda no momento da enunciação.

A segunda acepção do Perfeito Composto que se observou no objeto investigado é a de completitude ou completo. Trata-se de um determinado evento expresso pelo Perfeito Composto que o enunciador aproximou do momento da enunciação por meio de uma atualização temporal psicológica. Neste caso, a relevância desse evento subsiste para o enunciador, perdure ou não o resultado de tal ação ou evento no momento da enunciação. É por este motivo que, segundo Bertinetto (1986), o Perfeito Composto é a escolha aonde quer que o enunciador se refira a um processo recente. Esta evidência pode ser observada no exemplo de Bertinetto: ${ }^{6}$

\section{(f) Sono nato il 18 gennaio 1947}

no qual o enunciador que pronuncia essa frase se encontra em vida ainda no momento da enunciação. Este é o motivo pelo qual se pode explicar que não existe nenhuma restrição no que se refere à distancia temporal do momento do acontecimento sono nato com o momento da enunciação.

Neste sentido, o critério que determina o emprego do Perfeito Composto se apoia exclusivamente na relevância que o evento representa para o enunciador, no momento em que ele enuncia. Assim, tem-se o evento sono nato, que aconteceu em 1947, perdurando no momento da enunciação. 
Nesse outro efeito do Perfeito Composto, a acepção psicológica do enunciador traz para o momento da enunciação, devido a sua relevância atual, um evento acontecido há algum tempo. Nesta perspectiva, o momento de referência coincide com o momento da enunciação, tendo-se como resultado uma acepção aspectual de completitude do Perfeito Composto.

A terceira acepção do Perfeito Composto tratada neste ensaio é a Aorística, um efeito estilístico que ocorre sempre que o enunciador colocar o momento do acontecimento relacionado ao tempo físico, como se observa no seguinte exemplo de Bertinetto7:

\section{(g) Massimo ha mangiato il gelato dieci minuti prima.}

Nesse enunciado o marcador temporal mede o intervalo de tempo entre o final do evento ha mangiato e um instante que não coincide com o momento da enunciação. Por este motivo, este Perfeito Composto atribui uma acepção aorística ao enunciado.

Desse modo, pode-se indicar que a diferença entre o aspecto completo e o aorístico se dá através do evento acontecido e de sua valorização no momento de referência, que coincide com o momento da enunciação. No aspecto aorístico, valoriza-se o evento ligado ao fluir do tempo físico.

Observa-se, portanto, que o emprego do Perfeito Composto em um enunciado pode produzir diferentes efeitos estilísticos, conforme o marcador temporal ao qual esteja relacionado. Pode-se inferir que o envolvimento do Perfeito Composto com o marcador temporal utilizado é necessariamente enganchado no momento de referência e o momento de referência coincide ou não temporalmente com o momento da enunciação.

As nossas reflexões demonstram que o resultado desta relação poderá produzir um efeito estilístico de Perfeito Composto com valor aspectual ou de completitude, ou aorístico ou inclusivo. Todavia, a pesquisa acerca da função aspectual do Perfeito Composto não está concluída. Desse modo, os resultados que se apresentaram, até o momento, consideraram uma pequena série de usos aspectuais do Perfeito Composto relacionado com o momento da enunciação. É necessário, entretanto, lembrar que existe outro grupo de Perfeito Composto, com o momento de referência desenganchado do momento da enunciação, que está passando, ainda, por nosso processo de análise. 


\section{Referências bibliográficas}

ARAUS, M.L. G. Formas temporales del pasado en indicativo. Madrid: Arco Libros, 1995.

BERTINETTO, P.M. Tempo, aspetto e azione nel verbo italiano. Firenze: Accademia della Crusca, 1986.

BENVENISTE, E. Problemi di linguistica generale. Milano: Il Saggiatore 1994.

MAINGUENEAU, D. Elementos de linguística para o texto literário: leitura e crítica. São Paulo: Martins Fontes, 1996.

RENZI, L.; SALVI, G.; CARDINALETTI, A. Grande grammatica italiana de consultazione II. I sintagmi verbale, aggettivale, avverbiale. La subordinazione. Bologna: Mondadori, 2001.

SABATINI, F. La comunicazione e gli usi della lingua. Torino: Loescher, 1990. 